\section{Differential regulation of plasma proteins between members of a family with homozygous $\mathrm{HbE}$ and $\mathrm{HbE} \beta$-thalassemia}

\author{
Suchismita Halder, ${ }^{1}$ Tridip Chatterjee, ${ }^{2}$ \\ Amit Chakravarty, ${ }^{2}$ Sudipa Chakravarty, ${ }^{2}$ \\ Abhijit Chakrabarti ${ }^{3}$ \\ 1Biophysics \& Structural Genomics \\ Division, Saha Institute of Nuclear \\ Physics; 2Institute of Genetic Medicine \\ and Genomic Science, Kolkata, India \\ ${ }^{3}$ Crstallography and Molecular Biology \\ Division, Saha Institute of Nuclear \\ Physics, Kolkata, India
}

\begin{abstract}
In this report we've compared the plasma protein profiles of 4 individuals in a family. Father and the younger son both are hemoglobin $(\mathrm{Hb})$ E $\beta$-thalassemic $\{$ Cod 26 (G-A)/IVS 1-5 (G-C)\}, but the father never requires transfusion, whereas the younger son requires monthly blood transfusion. Mother and the elder son are $\mathrm{HbEE}$ \{Cod 26 (G-A)/Cod 26 (G-A) \} without any history of transfusion. Proteomic study was done on the plasma fraction of the blood following ammonium sulphate precipitation. Proteins were separated by 2D-gel electrophoresis, expression of proteins compared by densitometry and proteins identified by tandem MALDI mass spectrometry. Proteins responsible in hemolysis, hypercoagulation and hemoglobin scavenging have shown differential regulation, establishing the relation between the differences in the levels of plasma proteins with the progression of the disease phenotype, manifested in the extent of transfusion dependence of the patient.
\end{abstract}

\section{Introduction}

The hemoglobin $(\mathrm{Hb}) \mathrm{E}-\beta$ is one of the commonest forms of hemoglobinopathies worldwide. ${ }^{1}$ The $\mathrm{HbE}$ mutation is located near the junction between the first exon and the first intron of the $\beta$-chain gene. Nucleotide sequence change near the consensus splice site region activates a cryptic splice site, which is not normally used for mRNA processing. This new splice site competes with the normal splice site. Some mRNAs are still processed using the normal splice site and thus produce a protein with a Lys instead of a Glu at position 26. The variant $(\mathrm{HbE})$ is thus innocuous in its heterozygous and homozygous states. ${ }^{2}$ The pri- mary clinical importance of $\mathrm{HbE}$ trait arises when the $\beta^{\mathrm{E}}$ allele interacts with other $\beta$-thalassemia mutations leading to a moderate to severe anemia known as $\mathrm{HbE} \beta$-thalassemia. ${ }^{3}$ In this paper we are presenting a classical case which shows that, not only different $\beta$-thalassemia mutations can give rise to variety of clinical consequences, but also same $\beta$-thalassemia mutation upon interacting with $\beta^{\mathrm{E}}$ allele can lead to variety of clinical manifestation of the disease condition. Here, two members of the family (the father and the younger son) even after having identical $\beta$ chain mutation, shows marked difference in terms of clinical severity and transfusion requirement.

\section{Materials and Methods}

We describe clinical details of a thalassemic family showing an unusual and interesting pattern of blood transfusion requirement between two members of identical $\beta$ globin mutational background. In the family, the father (P1, Table 1) is HbE- $\beta$-thalassemic with no history of blood transfusion. Though his hemoglobin was found to be less than normal $(6.8 \mathrm{~g} / \mathrm{dL})$ never experienced any clinical complications and physiological manifestation of anemia, even after doing vigorous physical work. Mother (P2, Table 1) is HBEE and has no history of blood transfusion. Elder son (P3, Table 1) is also HbEE, like mother and never had blood transfusion. As per classical symptoms of HbEE patients, the mother (P2) and the elder son (P3) both maintain good hemoglobin level and are asymptomatic in terms of expression of anemic features. Younger son (P4, Table 1), is HBE- $\beta$ thalassemic like his father, however, is highly anemic and requires monthly blood transfusion, starting from an age of 8 months. We have also included a nonrelated $\mathrm{HbE}-\beta$ thalassemic sample (P5) having similar clinical features as that of the $\mathrm{P} 4$ to validate or confirm the plasma proteome of P4.

Peripheral blood samples were collected from every member of the above-mentioned family, patient and normal volunteers in vials containing $5 \mathrm{mM}$ ethylenediaminetetraacetic acid. Written consent was taken from adults and in case of children it was taken from the parents as per guidelines of institutional ethical committee. The handling of all human blood samples was carried out in accordance with the guidelines established by the Local Ethical Committee. For the patients P4 and P5 who are on regular blood transfusion, peripheral blood was taken after transfusion gap of 45 days, the maximum gap they could withstand. Plasma and red blood cells were separated using $75 \%$ percoll for the proteomic studies, as described earlier. ${ }^{4}$

As per protocol all members of the affected
Correspondence: Abhijit Chakrabarti, Crstallography and Molecular Biology Division, Saha Institute of Nuclear Physics, 1/AF Bidhannagar, Kolkata - 700064, India.

Tel.: +91.3323375345.49 (Ext. 1307)

Fax: +91.3323374637 .

E-mail: abhijit.chakrabarti@saha.ac.in; abhijit1960@gmail.com

Key words: HbE- $\beta$ thalassemia, blood transfusion, differential proteomics.

Contributions: $\mathrm{SH}, \mathrm{TC}$ contributed equally to this work. SH did all the proteomics work; SH, TC prepared the first draft of the manuscript; TC did all the mutation experiments and collected the clinical data; SC, AC, worked as clinical collaborators and corrected the manuscript; AC supervised the entire work and corrected the final version of the manuscript.

Conflict of interests: the authors declare no potential conflict of interests.

Acknowledgements and funding: we acknowledge the funding for this work from SPGHGD project, DAE, Government of India.

Received for publication: 22 July 2013.

Revision received: 18 November 2013.

Accepted for publication: 11 February 2014.

This work is licensed under a Creative Commons Attribution 3.0 License (by-nc 3.0).

(C) Copyright S. Halder et al., 2014

Licensee PAGEPress, Italy

Thalassemia Reports 2014; 4:1837

doi:10.4081/thal.2014.1837

family were evaluated for baseline clinical investigations, which are as follows: fetal hemoglobin ( $\mathrm{HbF}$ ), $\mathrm{HbA}_{0}, \mathrm{HbA}_{2}$, hemoglobin, mean cell volume, mean cell hemoglobin, mean cell hemoglobin concentration, red cell distribution width and hematocrit. The hematologic data ( $\mathrm{Hb}$ and complete blood count) were obtained by automatic analysis (Cell Counter: Medonic 530, cell counter: Medonic 530; EMerck, Darmstadt, Germany) and $\mathrm{Hb}$ variants $\left(\mathrm{HbA}, \mathrm{HbF}\right.$ and $\left.\mathrm{HbA}_{2} / \mathrm{E}\right)$ were estimated by high performance liquid chromatography (HPLC) (Bio-Rad Lab., Hercules, CA, USA) using manufacturer's protocol.

DNA was isolated from white blood cells, using a DNA isolation kit for mammalian blood (Qiagen, Venlo, The Netherlands). Patients were screened for five common $\beta$-thalassemia mutations of Eastern India ${ }^{5-7}$ like IVS1-1 (G-T), IVS1-5 (G-C), codon 8/9 (+G), codon 26 (G-A), and Fr. 41/42 (-TCTT). The screening was performed by polymerase chain reaction (PCR) based technique, amplification refractory mutation system (ARMS) as described by 0ld. ${ }^{8}$ Direct DNA sequencing of the $\beta$-globin gene was also done to further confirm the mutations. Salting out with $20 \%$ ammonium sul- 
Table 1. Clinical data of the members of the family in study.

\begin{tabular}{|c|c|c|c|c|c|}
\hline Clinical parameters & P1 (father) & P2 (mother) & P3 (elder brother) & P4 (younger brother) & P5 (unrelated sample) \\
\hline Hemoglobin (g/dL) & 6.8 & 11.2 & 11.4 & 4.1 & 5.7 \\
\hline MCV (fL) & 48.5 & 54.2 & 50.3 & 57.0 & 79.9 \\
\hline $\mathrm{MCH}(\mathrm{pg})$ & 17.2 & 21.1 & 21.2 & 16.6 & 27.8 \\
\hline MCHC (\%) & 35.4 & 38.9 & 42.2 & 29.2 & 34.9 \\
\hline Rdw (\%) & 29.0 & 23.6 & 22.2 & 26.4 & 32.4 \\
\hline Hct $(\%)$ & 19.3 & 26.8 & 27.1 & 14.2 & 16.6 \\
\hline $\mathrm{HbA}_{2} / \mathrm{E}(\%)$ & 83.2 & 73.6 & 90.3 & 17.8 & 28.1 \\
\hline $\mathrm{HbA0}(\%)$ & 8.1 & 3.6 & 2.1 & 70.3 & 36.8 \\
\hline $\mathrm{HbF}(\%)$ & 5.3 & 2.1 & 1.7 & 4.0 & 33.6 \\
\hline P3 (\%) & 3.3 & 5.3 & 5.1 & 4.7 & ND \\
\hline History of BT & No & No & No & $\begin{array}{l}1^{\text {st }} \text { BT on } 8 \text { months, } \\
\text { then on monthly BT }\end{array}$ & $\begin{array}{l}1 \text { st BT on } 1 \frac{1}{2} \text { years, } \\
\text { then on monthly BT }\end{array}$ \\
\hline
\end{tabular}

MCV, mean cell volume; MCH, mean cell hemoglobin; MCHC, mean cell hemoglobin concentration; Rdw, red cell distribution width; Hct, hematocrit; ND, not detected; BT, blood transfusion.

phate was done to deplete the high abundant proteins from the plasma fraction as described in our earlier work. ${ }^{9}$ The depleted plasma fraction was then dialyzed against $10 \mathrm{mM}$ Tris, 5 $\mathrm{mM} \mathrm{KCl}$, pH 7.5 , at $4^{\circ} \mathrm{C}$, which was then used for 2D gel experiments. The protein sample was then separated by 2D gel electrophoresis (Bio-Rad) and the gels were stained following the protocol as described in our earlier work and densitometry analysis done using the PDQuest (V 7.1) software package (Bio-Rad).

\section{Results and Discussion}

\section{Mutational studies}

The clinical features of the family members are given in Table 1. The HPLC results indicate that the father (P1), the younger son (P4) and the non-related sample $\mathrm{P} 5$ are $\mathrm{HbE}-\beta$-thalassemics and the mother (P2) and the elder son (P3) are HbEE. These data were reconfirmed by the results obtained from ARMSPCR. The genotype of the four members on the basis of $\beta$ globin mutations are following: P1 and P4 are Cod 26 (G-A) / IVS 1-5 (G-C), P2 and P3 are Cod 26 (G-A) / Cod 26 (G-A).

$\mathrm{P} 2$ and $\mathrm{P} 3$ are homozygous for $\mathrm{HbE}$, hence no other $\beta$ mutations were found in them, which confirm their homozygous state of $\mathrm{HbE}$. P1 and $\mathrm{P} 4$ have another $\beta$ mutation IVS 1-5 (G-C) along with Cod 26 (G-A), responsible for making them compound heterozygous i.e. HbE- $\beta$-thalassemia. These mutational studies also confirm that, P4, who is the main concern of this study, inherits $\mathrm{HbE}$ [Cod 26 (G-A)] allele from mother (P2) and other mutated $\beta$ [IVS 1-5 (GC)] allele from father (P1) (Figure 1).

\section{Differences in the fractionated plasma proteome}

On comparing the normalized intensities of

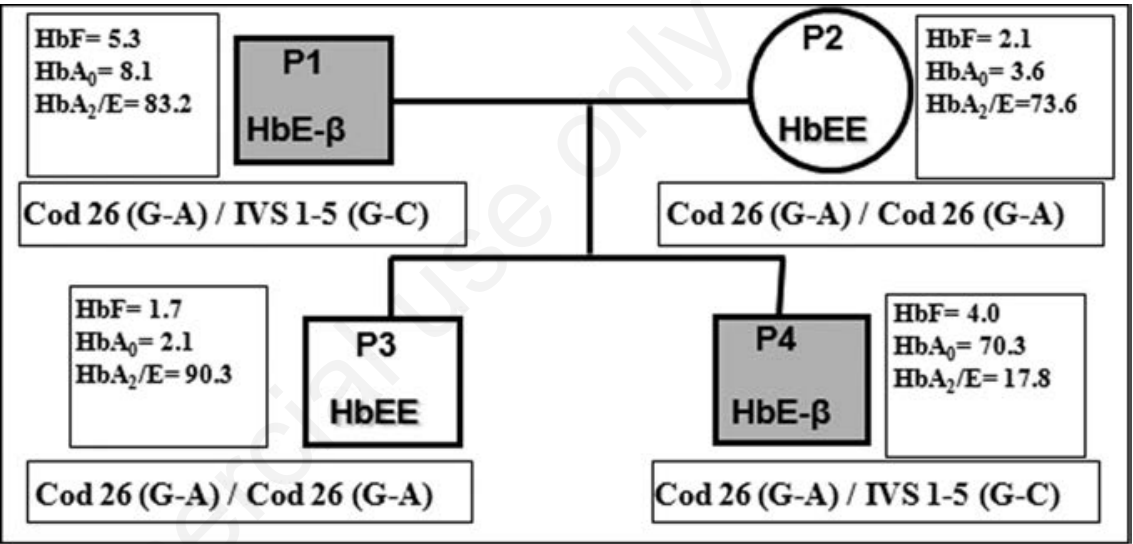

Figure 1. Pedigree of the family along with major clinical and mutational data. $\mathrm{Hb}$, hemoglobin.

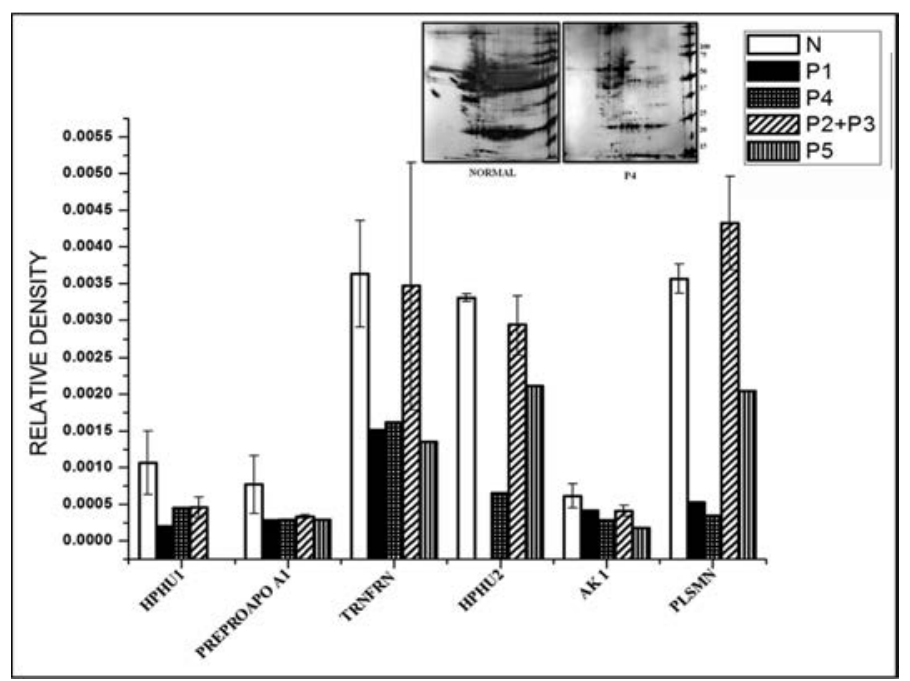

Figure 2. Histogram plots showing change in relative densities of the 6 differentially regulated proteins in the plasma fraction. Since this was a case study, statistical analysis on the test samples were not done. Deviations from the mean of two normal (empty bar) and homozygous $\mathrm{E}$ (in slanted striped bar) samples are shown. The inset shows a $2 \mathrm{D}$ gels of normal and P4. N, normal; P1, father; P4, younger son; P2+P3, averaged P2 (mother) and P3 (elder son); P5, unrelated HbE- $\beta$-thalassemic sample; HPHU1, haptoglobin precursor 1, PREPROAPO A1, preproapolipoprotein A1, TRNFRN, transferrin; HPHU2, haptoglobin precursor 2; AK 1, adenylate kinase 1; PLSMN, plasminogen. 
the protein spots of the gels in the five individual samples, few proteins have shown differential expression. Haptoglobin precursor 1 (HPHU1) and preproapolipoprotein A1 (LPHUA1) shows decrease in all five samples compared to the normal samples. On the other hand, the samples P4 and P5 who are heavily transfusion dependent show down regulation of haptoglobin precursor (HPHU2) and adenylate kinase 1 (Q5T9B7). HPHU1 and LPHUA1 show down regulation in all. The plausible explanation for the down regulation of haptoglobins could be due to the fact that erythrocytes are exposed to varying degrees of oxidative stress, leading to differential hemolysis. Haptoglobins in the plasma scavenge for free hemoglobin released due to hemolysis, thus leads to a decrease in the level of haptoglobin in these samples. Preproapolipoprotein A1 is found primarily on high-density lipoprotein cholesterol. It has been observed that the down regulation of apolipoprotein $\mathrm{Al}$ is related to the increase of pulmonary hypertension, which is a manifestation of acute or chronic hemolysis ${ }^{10,11}$ (Figure 2).

Transferrin (Q53H26) and plasminogen (Q5TEH4) show down regulation in the P1, P4 and P5. The extent of down regulation is lesser in P5, which could be attributed to the presence of very high level of $\mathrm{HbF}(33 \%){ }^{12}$ The lowering of the transferrin levels could be due to iron overload, commonly resulting from frequent blood transfusion..$^{13}$ Plasminogen is an inactive precursor of plasmin, and is involved in fibrinolysis. Chronic hypercoagulable state is observed in thalassemic patients undergoing regular transfusion, like in case of $\mathrm{P} 4$. Lowering of the plasminogen level could be a manifestation of this state. ${ }^{14}$ Since father does not take any transfusion, we can only assume that the decrease in plasminogen in father is due to the maintenance of homeostasis from oxidative stress produced in the blood.

The haptoglobin precursor (HPHU2) and adenylate kinase 1 (Q5T9B7_HUMAN) are the two proteins, which is seen to be down regulated only in P4 and P5 as compared to normal. In this case, haptoglobin precursor (HPHU2) can be explained in the same light as haptoglobin precursor (HPHU1). Adenylate kinase 1 in plasma has been reported to play a role in the irreversible breakdown of any adenosine diphosphate (ADP) accessible to it. The aggregation of platelets by ADP, in turn is thought to play a role in homeostasis and thrombosis. It is inferred that degradation of ADP leads to the reversal of aggregation. Hence the down regulation of adenylate kinase 1 is seen in case of the transfusion dependent patients, who are prone to thrombolytic events. ${ }^{15}$ As shown in earlier work, ${ }^{4}$ redox regulator proteins like, peroxiredoxin 2 (prdx2), thioredoxin, Cu-Zn superoxide dismutase and chaperones like hsp70 and $\alpha$ hemoglobin stabilizing protein show marked increase in erythrocyte cytosol and the extent of increase depends on the extent of $\mathrm{HbE}$ percentage present in the samples. It is seen in our earlier proteomic study ${ }^{4}$ that patients having $\mathrm{HbE}$ levels ranging in between $50-60 \%$ show higher changes in these proteins compared to those with $>80 \% \mathrm{HbE}$, as observed here in case of $\mathrm{P} 1$ with $83.2 \% \mathrm{HbE}$.

To summaries, we have seen that the genomics study of the family showed that P1 and P4 has the exactly identical mutation in their $\beta$ globin gene, but the father showed no clinical manifestation, whereas the younger son is severely anemic and requires blood transfusion every month. Proteomic study revealed that few plasma proteins, involved in hemoglobin scavenging, hemolysis or hypercoagulation show differential changes between the strongly transfusion dependent patients, P4 and P5 from those of normal individuals and the ones who do not need blood transfusions, P1, P2 and P3 indicating the changes to be specific to the disease conditions. Erythrocytes from the P4 and P5 undergo oxidative stress, are prone to hemolysis and found to have tendencies of hypercoagulation. Taken together, this report shows the importance of differential protein expressions in the clinical presentation of the disease as well as the modulators of globin synthesis. ${ }^{16}$ The combination of both genomic and proteomic approaches could provide a better understanding of the disease progression and pathophysiology.

\section{References}

1. Weatherall DJ, Clegg JB. Thalassemia - a global public health problem. Nat Med 1996;2:847-9.

2. Orkin SH, Kazazian HH Jr, Antonarakis SE, et al. Abnormal RNA processing due to the exon mutation of beta-E-globin gene. Nature 1982;300:768-9.

3. Ong-Ajyooth S, Suthipark K, Shumnumsirivath $\mathrm{D}$, et al. Oxidative stress and antioxidants in beta-thalassaemia/haemoglobin E. J Med Assoc Thai 1987;70:270-4.

4. Bhattacharya D, Saha S, Basu S, et al. Differential regulation of redox proteins and chaperones in $\operatorname{HbE} \beta$ thalassemia erythrocyte proteome. Proteomics Clin Appl 2010;4:480-8.

5. Kukreti R, Dash D, Vineetha KE, et al. Spectrum of $\beta$-thalassemia mutations and their association with allelic sequence polymorphisms at the $\beta$-globin gene cluster in an Eastern Indian Population. Am J Hematol 2002;70:269-77.

6. David H, Chui K, Hardison R, et al. An electronic database of human hemoglobin variants on the World Wide Web. Blood 1998;91:2643-54.

7. Varawalla NY, Old JM, Sarkar R, et al. The spectrum of beta-thalassaemia mutations on the Indian subcontinent: the basis for prenatal diagnosis. Br J Haematol 1991; 78:242-7.

8. Old JM. Detection of mutations by the amplification refractory mutation system (ARMS). Methods Mol Biol 1991;9:77-84.

9. Saha S, Halder S, Bhattacharya D, et al. Fractional precipitation of plasma proteome by ammonium sulphate: case studies in leukemia and thalassemia. J Proteomics Bioinform 2012;5:163-71.

10. Morris CR. Mechanisms of vasculopathy in sickle cell disease and thalassemia. Hematology 2008;13:177-85.

11. Morris CR, Kuypers FA, Kato GJ, et al. Hemolysis-associated pulmonary hypertension in Thalassemia. Ann N Y Acad Sci 2005;1054:481-5.

12. Rees DC, Porter JB, Clegg JB, et al. Why are hemoglobin $\mathrm{F}$ levels increased in $\mathrm{HbE} / \beta$ thalassemia? Blood 1999;94:3199-04.

13. Camaschella C, Poggial E. Towards explaining "unexplained hyperferritinemia”. Haematologica 2009;94:307-9.

14. Eldor A, Rachmilewitz EA. The hypercoagulable state in thalassemia. Blood 2002; 99:36-43.

15. Haslam RJ, Mills DCB. The adenylate kinase of human plasma, erythrocytes and platelets in relation to the degradation of adenosine diphosphate in plasma. Biochem J 1967;103:773-8.

16. Rund D, Fucharoen S. Genetic modifiers in hemoglobinopathies. Curr Mol Med 2008;8:600-8. 